\title{
Intractable Temporal Lobe Epilepsy from Benign and Malignant Amygdalo-hippocampal Anglioglioma; Icroneurosurgical Management. A Report of Two Cases with Short Literature Review
}

\author{
FH CHOWDHURYa ${ }^{\mathrm{a}}$ MR HAQUE ${ }^{\mathrm{b}}$, NC SHAHA ${ }^{\mathrm{c}}, \mathrm{KA} \mathrm{KAWSAR}^{\mathrm{d}}$
}

\begin{abstract}
Summary:
Epilepsy patients are usually managed medically but some cases are resistant to medical treatment and needs surgical treatment. Temporal lobe epilepsy (TLE) is commonly intractable. The underlying cause may be mesial temporal sclerosis(MTS), cortical dysplasia(CD), tumors (ganglioglioma, dysembryoplastic neuroepithelial tumorDNET), post traumatic gliosis, infection (tuberculosis) parasitic infestation (schistosomiasis, neurocystocercosis) etc. In this type of epilepsy surgery is the treatment of choice (even there is no symptoms other than seizure). Here we report two cases of surgically treated TLE that were due to low grade ganglioglioma and high grade ganglioglioma. In both cases
\end{abstract}

Introduction:

About 20\%-30\% epilepsies are drug resistant and intractable. ${ }^{1,2}$ In this group of patient some form of surgery is usually needed either to cure epilepsy or to improve living standard by better control of epilepsy with drugs. The idea of surgical treatment for epilepsy is not new. However, widespread use and general acceptance of this treatment has only been achieved during the past three decades. Improvements in imaging resulted in an increased ability for preoperative identification of intracerebral and potentially epileptogenic lesions. ${ }^{3}$ High resolution magnetic resonance imaging plays a major role in structural imaging. EEG (Especially video), MRI and other

a. Dr. Forhad Hossain Chowdhury, FCPS; Neurosurgeon, Dept. of Neurosurgery, Dhaka Medical college Hospital, Dhaka.

b. $\quad$ Dr. Md. Raziul Haque, FCPS; Associate Professor, Dept. of Neurosurgery, Dhaka Medical college Hospital, Dhaka.

c. Dr. Narayan Chandra Shaha, Associate Professor, Dept. of Pediatrics, Dhaka Medical college Hospital, Dhaka.

d. Dr. Khandkar Ali Kawsar, Resident, Dept. of Neurosurgery, Dhaka Medical College Hospital, Dhaka.

Address of Correspondence: Chowdhury Forhad Hossain, FCPS,C6, Rupayan angel, 152 Shantinagar, Dhaka, Bangladesh. Phone +8801711949570, e-mail- forhadchowdhury74@yahoo.com

Received: 19 August, 2010

Accepted: 10 March, 2013 the only presenting symptoms was complex partial seizure (Psychomotor epilepsy) for which they underwent scalp EEG (Electro Encephalography) and MRI (Magnetic Resonance Imaging) of brain. Both patients were managed by complete tumor excision with amygdalohippocampectomy plus standard anterior lobectomy. One patient with high grade ganglioglioma recurred within two months of operation and expired within five months. The other case was seizure and disease free till last follow up.

Key Word: Ganglioglioma, Intractable temporal lobe epilepsy, Amygdalohippocampectomy, Lesionectomy.

(J Banagladesh Coll Phys Surg 2013; 31: 214-218)

functional imaging usually help in identification of epileptogenic zone or foci ${ }^{2}$. Today, epilepsy surgery is more effective and conveys a better seizure control rate. It has become safer and less invasive, with lower morbidity and mortality rates ${ }^{3}$.

Here we report our initial experience of epilepsy surgery (amygdalohippocampectomy) with two medial temporal lobe tumor (ganglioglioma) in Bangladesh.

Case presentation:

Case 1

A 11 year old right handed school girl presented with sudden development of uneasiness, perception of smell of kerosene, followed by loss of awareness of surroundings for a period of 1-2 minutes for last 20 months. Initially the episode of seizure was 3-4 attack per week but later it was 10-12 attack per day. She was on adequate doses of two anti epileptic drug (AED) (Carbamazipine and sodium valproate) for last 16 months but seizure frequency was not reduced rather increased. She had no history of headache, vomiting, visual disturbances, limb weakness or gait disturbance. She had no significant past events related to present disease. There was no significant event in her birth process and family history was negative for such type 
of disease. On complete, physical, neurological examinations including mental functions (neuropsychiatric evaluation) revealed no abnormality. Repeated scalp EEG recording showed epileptic spikes originating from right centro-temporal region. MRI of brain in epilepsy protocol showed features of right amygdalo-hippocampal mass lesion $(1 \mathrm{x} 1.5 \mathrm{x} 1 \mathrm{~cm})$ suggestive of low grade glioma (Fig.-1 A\&C).

She underwent complete tumor removal with amygdalohippocampectomy and standard anterior temporal lobectomy through right temporal craniotomy and trans middle temporal gyrus approach. Histopathological examination revealed grade-1 ganglioglioma. Postoperatively she recovered uneventfully. She was put on carbamazipine $100 \mathrm{mg}$ tablet thrice daily that was tapered and stopped 4 months after operation. She has been seizure free for last eighteen months. Post operative MRI of brain at the end of $4^{\text {th }}$ months after operation showed no residual or recurrent tumor (Figure1B\&D) and there was no visual field defect or neuropsychiatric deficit.

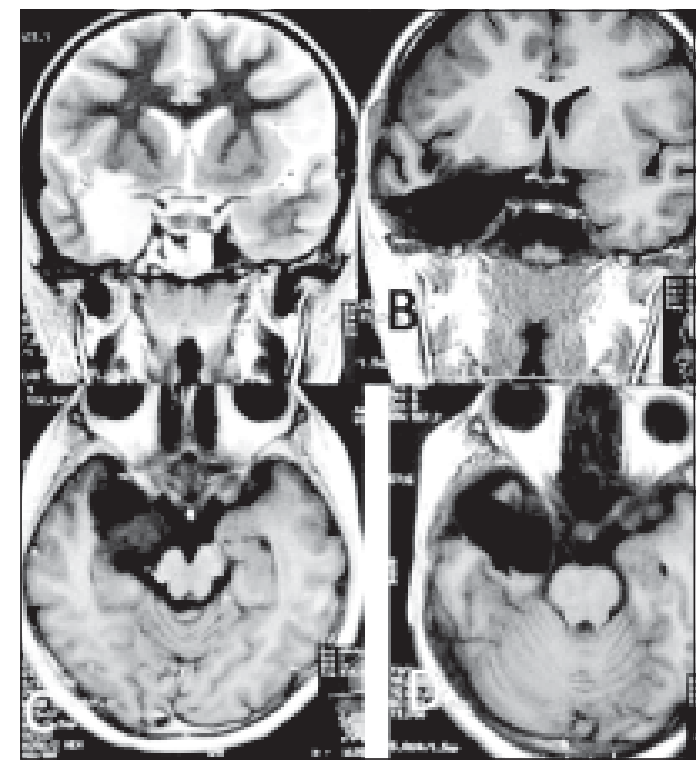

Fig.-1: Preoperative MRI of brain;A-T2W coronal image \& $C-T 1 W$ axial image showing right amygdalo-hippocampal tumor. Postoperative MRI of brain; B- T1W coronal image and $D-T 2 W$ axial image after amygdalohippocampectomy with tumor removal and standard anterior temporal lobectomy.

\section{Case 2:}

A forty one years old right handed cultivator presented with history of sudden onset uneasiness followed by smell of rotten meat for a period of 10-15 sec for last 2 months with 7-8 episodes of these events per day. He had no headache, vomiting, visual disturbances, limb weakness or gait disturbances. On neurological examinations including mental functions were normal except left sided extensor planter and positive Hoffman signs. Other physical and systemic examinations revealed no abnormality. Scalp EEG recording showed epileptic spikes originating from right centro-temporal region. MRI of brain showed features of right amygdale and hippocampal mass lesion $(2 \times 1.5 \times 1 \mathrm{~cm})$ suggestive of glioma that was compressing right cerebral peduncle (Fig.-2 A\&B).

He underwent amygdalohippocampectomy with lesionectomy plus standard anterior temporal lobectomy through right temporal craniotomy and trans middle temporal gyrus approach. Histopathology revealed grade-3 (anaplastic) ganglioglioma. Postoperatively he developed left sided hemiparesis due to operative site hematoma showed on immediate post operative CT scan of brain (Fig. 2C) that recovered within seven days. She was put on carbamazipine 100mg tablet thrice daily and advised for radiotherapy but patient party refused radiotherapy. He was seizure free for 02 months but after that the seizure events returned along with left sided weakness and features of raised intracranial pressure. Post operative MRI of brain at the end of $4^{\text {th }}$ months showed huge recurrence of tumor(Figure2D). The patient expired five months after operation.

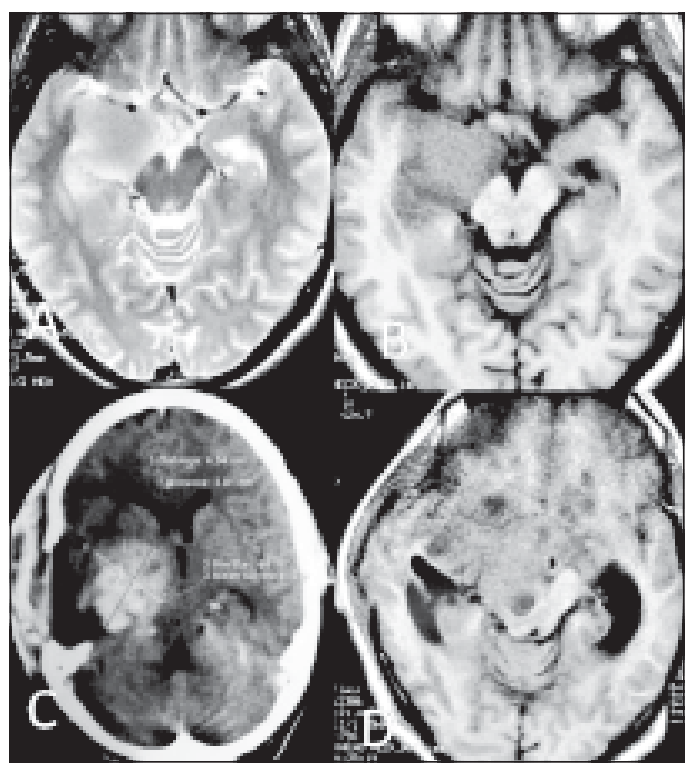

Fig.-2: A-Preoperative MRI of brain A-T2 weighted axial image and $B-T 1 W$ axial image showing right amygdalohippocampal tumor growth suggestive of glioma. CImmediate post operative CT scan of brain axial image showing haematoma inoperating site that caused temporary hemiplegia .D-Post operative MRI of brain $T 1 \mathrm{~W}$ axial image(04 months after operation) showing huge recurrence of Grade-III ganglioglioma with distortion of midbrain. 


\section{Discussion:}

Intractable epilepsy patient is a burden for the patient himself, family \& society and also to physician. Where indicated a properly done surgery can cure epilepsy or at least alleviates patients lifestyle with better control of seizure by drugs. William MacEwen (1848-1924) and Victor Horsley (1857-1916) in London were the first to localize and remove epileptogenic lesions, as identified by their symptomatogenic zone, according to the pioneering work of John Hughlings Jackson (18351911). ${ }^{3}$ The first epileptic surgery done by Sir Victor Horsley in 1887 was a case of intractable epilepsy from post traumatic gliosis. After a long dormant stage epilepsy surgery developed tremendously in last three decades. ${ }^{3}$ Among the drug resistant intractable epilepsy, temporal lobe epilepsy is the commonest epilepsy (about $80 \%$ ) and it responds beautifully to surgery. ${ }^{1,2}$ Common causes of intractable surgical epilepsy are cortical dysplasia (CD), MTS, temporal lobe and other lobe tumors (DNET, ganglioglioma and other), cortical atrophy, stroke, trauma, vascular lesion( AVM, cavernoma) etc. 1,3,4 EEG (especially video EEG) and good quality MRI are enough for identification of epileptogenic lesion, zone or focus. Only in a few number of cases fMRI (Functional MRI), PET (Positron Emission Tomography) or SPECT (Single Photon Emission Tomography) are need to aid in localization. ${ }^{1,3,4}$

Common surgical procedure for temporal lobe epilepsy are anterior temporal lobectomy(ATL), amygdalohippocampectomy(AH) through middle or inferior temporal gyrus approach (Transcortical), trans-sylvian selective amygdalohippocampectomy, trans middle temporal gyrus standard ATL +AH, focal cortical excision in cortical dysplasia (CD). 1,3,4,5 In temporal lobe epilepsy surgery amygdale is excised with hippocampus even though amygdale is not diseased in most of the cases as it decreases the electrical threshold of TLE and potentiate in generation of epilepsy.

In case- 1 the patient was suffering from intractable TLE. Imaging confirmed a epileptogenic lesion in the amygdala and hippocampal area which was a low grade ganglioglioma. Low grade ganglioglioma is one of the common benign lesions in this area causing TLE especially in children for which surgery is needed. ${ }^{4}$ Appropriate surgical intervention is usually curative for both epilepsy and tumor. In case- 2 anaplastic ganglioglioma in amygdale and hippocampus is less common cause of TLE. When occurs, presentation may be with epilepsy but clinical features progress quickly. Surgical treatment confirms histopathology along with palliation of symptoms. Radiotherapy improves a little. Symptoms recur along with other features suggestive of rapidly growing mass in intracranial space which is usually fatal.

We went for amygdalohippocampectomy with lesionectomy plus standard anterior temporal lobectomy in both cases but selective amygdalohippocampectomy with lesionectomy could be another surgical option to these lesions. ${ }^{3}$ Size of the lesion, possibility of different pathology, narrow space through trans-sylvian rout and possibility of manipulation and damage of critical vessel and neural structures and most importantly less familiarity of the approach along with less success rate of amygdalohippocampectomy in controlling epilepsy helped us to take decision in favor of trans middle temporal gyrus approach amygdalohippocampectomy with lesionectomy plus standard anterior temporal lobectomy instead of selective amygdalohippocampectomy in the hope to cure epilepsy as well as the lesion. It has been suggested that the amount of tissue resected in mesio-temporal operations is crucial for surgical success in mesial TLE. ${ }^{6-9 \& 10}$ In a randomized, prospective study comparing the trans-sylvian with the transcortical approach, seizure outcome was similar. ${ }^{11,12}$ Middle temporal gyrus approach does not usually damage the optic radiation (Meyer loop) unless excessive backward and upward retraction or misdirection of transcortical incision. ${ }^{13}$ In all of our cases we found no visual field defect both clinically and in perimetry.

Generally, complication rates of epilepsy surgery are relatively low $^{2}$ and thought to be acceptable, with approximately 1 to $2 \%$ permanent morbidity. ${ }^{14}$ The rate of minor complications was $3.6 \%$, and the rate of major complications was $1.26 \%$ in the Zürich series of 478 amygdalohippocampectomies. Persisting hemiparesis occurred in $0.84 \%$ as a result of choroidal infarcts of the internal capsule. ${ }^{15}$ Typical neurological complications after surgery for TLE include temporary dysphasia or hemiparesis as caused by manipulationinduced brain swelling or brain contusion, small vessel infarction, and hemorrhage. There are the classic surgical problems such as infection, thrombosis, etc., in the range 
of 2 to $4 \%$, which rarely cause permanent damage. ${ }^{14}$ The mortality rate is clearly below $1 \%$ in most series. In our case- 2 post operatively patient developed transient hemiparesis that was due to haematoma in the operative field compressing one of the crus cerebri.

About 70\% patients become seizure free after temporal lobe epilepsy surgery and another 15-25\% patient will have at least a $90 \%$ reduction in seizure frequency. ${ }^{2}$ Seizure control rate in MTS after surgery is excellent. 3,4 In certain developmental tumors, e.g., gangliogliomas and dysembryoplastic neuroepithelial tumors, which can be treated with excellent seizure-control rates in most patients. ${ }^{16}$ Also, certain types of low-grade gliomas (e.g., isomorphic subtype of low-grade astrocytoma, pilocytic astrocytoma) can be operated on with excellent results. ${ }^{17-20 \& 21}$ In a series limited to preoperatively tailored resections for lesional (nonsclerotic) mesial TLE, satisfactory seizure control was obtained in $86 \%$ of patients. ${ }^{22}$ Outcome with lesionectomy and corticectomy was excellent, especially when a tumor was present (95\% satisfactory seizure control). ${ }^{23}$ Although it depends more on patient selection than surgery, it should be noted that operating on children and adolescents with epilepsy is extraordinarily promising with respect to seizure control and neuropsychological and psychosocial outcomes. ${ }^{5,24-27 \& 28}$

'Engel grading' system is used for assessment of outcome of epilepsy surgery. For effective initiation and implementation of epilepsy surgery program by a team formed of epileptologist, neuropathologist, neurophysiologist, neuroradiologist and neurosurgeon the facilities of EEG (especially video EEG), MRI and sometimes other imaging facilities along with cooperation from other specialty are very essential.

\section{References:}

1. Greenberg MS,MD. Seizures. In Greenberg MS,MD(eds).Hand book of Neurosurgery. $5^{\text {th }}$ edition, Newyork, Thieme,2001; pp 254-284.

2. Lowenstein DH:Seizures and Epilepsy,In Fauci AS ,MD.,Braunwald E, MD.,Kasper DL,MD.,Hauser SL, MD., Longo DL, MD., Jameson JL, MD., Loscalzo JL,MD(eds): Harrison's principles of internal medicine, VolII,17 ${ }^{\text {th }}$ edition. Newyork, McGrawHill, pp 2494-2512.

3. Schramm J, MD.,Clusmann H, MD. Surgery of epilepsy. Neurosurgery 2008;62[SHC Suppl 2]:463-481.

4. Harvey S.,Cross JH,Shinnar S.,Matheren BW.,The ILAE Pediatric Epilepsy Surgery Survey Taskforce.Defining the spectrum of international practice in pediatric epilepsy surgery patients.Epilepsia,2008;49(1):146-155.

5. Clusmann H, Kral T, Gleissner U, Sassen R, Urbach H, Blümcke I, Bogucki J, Schramm J: Analysis of different types of resection for pediatric patients with temporal lobe epilepsy. Neurosurgery 2004 54:847-859.

6. Awad IA, Katz A, Hahn JF, Kong AK, Ahl J, Lüders H: Extent of resection in temporal lobectomy for epilepsy. I. Interobserver analysis and correlation with seizure outcome. Epilepsia1989; 30:756-762.

7. Bonilha L, Kobayashi E, Mattos JP, Honorato DC, Li LM, Cendes F: Value of extent of hippocampal resection in the surgical treatment of temporal lobe epilepsy. Arq Neuropsiquiatr 2004, 62:15-20, 2004.

8. Nayel MH, Awad IA, Luders H: Extent of mesiobasal resection determines outcome after temporal lobectomy for intractable complex partial seizures. Neurosurgery1991; 29:55-61.

9. Renowden SA, Matkovic Z, Adams CB, Carpenter K, Oxbury S, Molyneux AJ, Anslow P, Oxbury J: Selective amygdalohippocampectomy for hippocampal sclerosis: Postoperative MR appearance. AJNR Am J Neuroradiol 1995;16:1855-1861.

10. Wyler AR, Hermann BP, Somes G: Extent of medial temporal resection on outcome from anterior temporal lobectomy: A randomized prospective study. Neurosurgery 1995;37: 982-991.

11. Lutz MT, Clusmann H, Elger CE, Schramm J, Helmstaedter C: Neuropsychological outcome after selective amygdalohippocampectomy with transsylvian versus transcortical approach: A randomized prospective clinical trial of surgery for temporal lobe epilepsy. Epilepsia2004; 45:809-816.

12. Schaller C, Jung A, Clusmann H, Schramm J, Meyer B: Rate of vasospasm following the transsylvian versus transcortical approach for selective amygdalohippocampectomy. Neurol Res 2004;26:666-670.

13. Chowdhury FH, Khan AH. Anterior and lateral extension of optic radiation and safety of amygdalohippocampectomy through middle temporal gyrus: A cadaveric study of 11 cerebral hemispheres. Asian J of Neurosurg 2010; 4 : 78-82.

14. Behrens E, Schramm J, Zentner J, König R: Surgical and neurological complications in a series of 708 epilepsy surgery procedures. Neurosurgery1997; 41:1-10.

15. Wieser HG: Selective amygdalohippocampectomy has major advantages, in Miller JW, Silbergeld DL (eds): Epilepsy Surgery: Principles and Controversies. New York, Taylor \& Francis, 2006, pp 465-478.

16. Pilcher WH, Silbergeld DL, Berger MS, Ojemann GA: Intraoperative electrocorticography during tumor resection: Impact on seizure outcome in patients with gangliogliomas. J Neurosurg 1993;78:891-902.

17. Blümcke I, Luyken C, Urbach H, Schramm J, Wiestler OD: An isomorphic subtype of long-term epilepsy-associated astrocytomas associated with benign prognosis. Acta Neuropathol (Berl) 2004; 107:381-388. 
18. Daumas-Duport C, Scheithauer BW, Chodkiewicz JP, Laws ER, Vedrenne C: Dysembryoplastic neuroepithelial tumor: A surgically curable tumor of young patients with intractable partial seizures. Report of thirty-nine cases. Neurosurgery1988; 23:545-556.

19. Luyken C, Blümcke I, Fimmers R, Urbach H, Elger CE, Wiestler OD, Schramm J: The spectrum of long-term epilepsyassociated tumors: Longterm seizure and tumor outcome and neurosurgical aspects. Epilepsia2003; 44:822-830.

20. Morris HH, Matkovic Z, Estes ML, Prayson RA, Comair YG, Turnbull J, Najm I, Kotagal P, Wyllie E: Ganglioglioma and intractable epilepsy: Clinical and neurophysiologic features and predictors of outcome after surgery. Epilepsia 1998;39:307-313.

21. Schramm J, Kral T, Kurthen M, Blümcke I: Surgery to treat focal frontal lobe epilepsy in adults. Neurosurgery 2002;51:644-655.

22. Clusmann H, Kral T, Fackeldey E, Blümcke I, Helmstaedter C, von Oertzen J, Urbach H, Schramm J: Lesional mesial temporal lobe epilepsy and limited resections: Prognostic factors and outcome. J Neurol Neurosurg Psychiatry 2004; 75:1589-1596.
23. Schramm J, Kral T, Grunwald T, Blümcke I: Surgical treatment for neocortical temporal lobe epilepsy: Clinical and surgical aspects and seizure outcome. J Neurosurg 2001; 94:33-42.

24. Blume WT: Temporal lobe epilepsy surgery in childhood: Rationale for greater use. Can J Neurol Sci 1997; 24:95-98.

25. Gleissner U, Sassen R, Lendt M, Clusmann H, Elger CE, Helmstaedter C: Pre- and postoperative verbal memory in pediatric patients with temporal lobe epilepsy. Epilepsy Res 2002;51:287-296.

26. Kral T, Kuczaty S, Blümcke I, Urbach H, Clusmann H, Wiestler OD, Elger C, Schramm J: Postsurgical outcome of children and adolescents with medically refractory frontal lobe epilepsies. Childs Nerv Syst2001; 17:595-601.

27. Mathern GW, Giza CC, Yudovin S, Vinters HV, Peacock WJ, Shewmon DA, Shields WD: Postoperative seizure control and antiepileptic drug use in pediatric epilepsy surgery patients: The UCLA experience, 1986-1997. Epilepsia1999;40:17401749.

28. Westerveld M, Sass KJ, Chelune GJ, Hermann BP, Barr WB, Loring DW, Strauss E, Trenerry MR, Perrine K, Spencer DD: Temporal lobectomy in children: Cognitive outcome. J Neurosurg 2000; 92:24-30. 